\title{
An exploratory study of the experience of fibromyalgia diagnosis in South Africa
}

\author{
Silvie Cooper and Leah Gilbert
}

Department of Sociology, University of the Witwatersrand, Private Bag 3, Wits, 2050, Johannesburg, South Africa

\begin{abstract}
Within the conceptual framework of 'medically-ill-defined' conditions, this article focuses on the experiences of 'diagnosis' through a narrative analysis of fibromyalgia (a chronic musculoskeletal pain disorder) in South Africa. In-depth interviews were used to collect narratives from 15 participants. The findings show how the contested and confusing experience of fibromyalgia diagnosis can be understood, by viewing the interactions that patients have with their practitioners, families, peers and colleagues. The currency of fibromyalgia as a diagnosis and the inequalities present in the South African health care system characterise the experiences of symptom recognition, diagnosis and treatment. The analysis reveals how those living with fibromyalgia search for diagnosis, and struggle to maintain legitimacy for their experience in the complex constellation of porous symptoms that appear infrequently. The findings of this study confirm the existing evidence that shows fibromyalgia to be a challenging illness experience, which is attributed to the lack of clarity and legitimacy, and high contestation that surrounds the condition. Additionally, this study presents the ways that limited access to diagnosis and treatment for fibromyalgia in the South African context shapes this specific illness experience, and the value of using narrative approaches to gain insight into how people live with hidden and poorly understood conditions in this environment.
\end{abstract}

Keywords: chronic illness and disability, experiencing illness and narratives, narrative analysis, sociology of health in developing countries

\section{Introduction}

Fibromyalgia is a chronic musculoskeletal pain condition that is characterised by uncertainty in the realms of diagnosis, prognosis and treatment. Fibromyalgia, like many other chronic conditions, falls under the broad category of 'medically-ill-defined' conditions or 'Medically Unexplained Symptoms' (MUS) that are distinguished as being 'incompletely biomedicalized' (Dumit, 2006; Jutel, 2010). The conditions are 'contested' and patients are continually challenged to respond to their symptoms in ways that convince themselves, practitioners, institutions and social networks that their experience is legitimate, and medically and socially real (Madden and Sim, 2016).

Ablin et al. (2012) note that fibromyalgia (also known as FM, or fibromyalgia syndrome (FMS)) is defined as 'chronic widespread pain (CWP) with allodynia or hyperalgesia to pressure pain, and is classified as one of the largest group of soft tissue pain syndromes' (p. 585). Symptoms commonly include 'chronic, diffuse, generalized musculoskeletal pain, and aches and stiffness that occur in the absence of joint inflammation or tissue damage' (Cunningham and Jillings, 2006: 258). There is also uncertainty surrounding the trajectories and treatments related to the condition, as well as multiplicity in the manifestation of symptoms. In 1990, the American College of Rheumatology (ACR) developed diagnostic criteria for fibromyalgia, and these were updated in 2010 to clarify current understandings of the condition (Wolfe, 2010). 
Pain and exhaustion are a frequent part of ordinary human experience. With fibromyalgia, however, these symptoms are interpreted as being abnormal and this represents a critical shift in their meaning. The diagnosis generates both support and derision, as the symptoms of pain and exhaustion are familiar and ordinary for many people, however, they are intolerable for those with the condition. For this reason, fibromyalgia can be invisible, and diagnosis relies heavily on the patient's telling of symptoms and practitioners' willingness to take the experience seriously and define it as illness. Still, there is sufficient evidence for the condition to exist as a medical diagnosis (Åsbring and Närvänen, 2004). MUS diagnosis is strongly connected to the subjective experience of the patient and the ability to communicate symptoms in a manner that can be correctly absorbed by the practitioner during the consultation. This mechanism does not differ from general diagnostic processes (Greco, 2012; Jutel, 2010). However, fibromyalgia pain is simultaneously distinct and appears alongside other conditions and so, as Berger et al. (2007) argue, the condition is 'typically difficult to diagnose. While various tests may be ordered to rule out other possible causes of patients' symptoms, such as rheumatoid arthritis and lupus, none is sufficiently sensitive or specific to establish a diagnosis of FMS' (p. 1498).

According to Barker (2011), between 2 and 5 percent of the US population live with fibromyalgia. The ratio of female to male patients is between 6:1 and 9:1 (Barker, 2011; Sim and Madden, 2008). In South Africa (SA), fibromyalgia is still being established as a diagnostic category and an area of research. In this milieu, chronic pain is viewed as being a clinical issue, rather than a contextual experience. It is unclear how many people are affected by fibromyalgia in SA, but it is estimated that the prevalence rate is around 3 percent in the general population (Govender, 2004). The lack of statistical evidence is indicative of the status of fibromyalgia in SA, both medically and socially. Therefore, SA provides a useful context in which to unpack and investigate issues that surround medically ill-defined conditions, such as fibromyalgia. The experience of fibromyalgia in SA, with the inequities found in health care provision (Eyles et al., 2015), means that behaving as a health care consumer in this context and seeking diagnosis from multiple practitioners is driven by the possession of fiscal resources and the capacity to articulate experiences in interpretable ways. Pursuit of an elusive diagnosis is consequently undertaken with access to resources that are not available to all. The divisions between public and private health care that characterise this country (Coovadia et al., 2009; Mclntyre et al., 2007; Stuckler et al., 2011) therefore shape this process, as will be shown in this article.

Diagnosis has a deeply rooted place in the experience of illness, as a momentary or continuous event (Mik-Meyer and Obling, 2012; Price and Walker, 2014). The event affords access and meaning to a person whose symptoms are recognised as abnormal by themselves and their context (Dommerholt and Issa, 2010). The centrality of biomedicine in society is evident in diagnostic procedures, with medical skill, knowledge, techniques and technologies being favoured as the means through which a patient, their symptoms and experiences are validated (Greco, 2012; Jutel and Nettleton, 2011). This link between medical legitimacy and access to diagnosis is highly relevant in $\mathrm{SA}$, where the reliance on private medical aid $^{1}$ to access health care services drives help-seeking behaviours. The context

\footnotetext{
${ }^{1}$.'Medical aids' are private companies that provide medical insurance to its members who have access to private health care providers and facilities. In SA, less than 20 percent of the population belong to a 'medical aid' scheme - this means that the rest of the population has to rely on an overburdened and inadequate public health service (Coovadia et al., 2009).
} 
illustrates these processes, where recognition and legitimacy, credibility, and diagnosis and practitioner encounters all interweave through patient narratives and detail the ways people pursue and explain fibromyalgia diagnosis in their illness experience.

The status and nature of the diagnosis of fibromyalgia has a real impact on people's abilities to make sense of their illness. It also affects their capacity to articulate their experience to others and to receive medical and social support (Barker, 2011; Cooper and Gilbert, 2016; Skuladottir and Halldorsdottir, 2011; Werner and Malterud, 2003). Gaining access to practitioners and treatments depends on the possession of a recognised diagnosis and the presence of practitioners who are accepting of that diagnosis in the health care environment and culture (Werner et al., 2003).

Diagnosis is necessary for the distinction between 'illness' and 'disease' to occur (Jutel, 2010), since it marks a significant shift from a personal experience to a medical encounter. 'Illness' is individually experienced in the cultural interpretation of pain and discomfort as problematic and in need of intervention (Lupton, 2003). 'Disease', having sought consultation with a health care practitioner, is offered as an explanation for illness under the new guise of medical diagnosis. Jutel (2010) further emphasises the crucial distinction between illness and disease in arguing that 'disease labels enable access to services and status that are not otherwise available' (p. 231).

In $\mathrm{SA}$, this process is further complicated by the limitations placed on access to health systems, services, providers and practitioners that can fund and fuel the pursuit of this diagnosis. Chetty et al. (2012), like Padarath et al. (2003), also see the lack of trained personnel as a challenge, and the variations in patient access to care that mirror socioeconomic boundaries in SA. Even when access to a diagnosis has been obtained, treatment may be elusive, and the label does not 'guarantee access to the most appropriate drugs, as financial and [supply chain] constraints, and [limited] formulary in the public sector [as well as] restricted reimbursement in the private sector limit access to appropriate medications' (Chetty et al., 2012: 312). This last factor featured clearly throughout the research described herein, in that access to treatment became a salient issue across the study population. Fibromyalgia as an illness experience requires much investment - financial and otherwise - on the part of the patient, the practitioner, and the health care systems with which they interact. Demonstrating how fibromyalgia diagnosis occurs in this context is an important avenue for revealing and explaining the experiences of those living with the condition.

There is a nascent body of literature related to the subject in SA, however, most studies focus on the development of clinical guidelines for diagnosing, managing and treating pain conditions, such as fibromyalgia (Govender et al., 2011; Namane, 2013; Raff et al., 2014). Engagement with the actual illness experience as it is produced in a specific social reality is limited in this literature, and patient perspectives are rarely used. While acknowledging the growing breadth of research that offers insight into chronic illness experience generally and fibromyalgia specifically, this article aims to address the particular dearth of patients' perspectives of the condition in SA. In the presence of predominantly clinically focused knowledge, research that aims to understand how people explain, pursue and embody their condition is a necessary and important contribution. This article explores the complexity of attaining a diagnosis of fibromyalgia in SA through the narratives of people living with the condition. 


\section{Methodology}

Presented herein are the findings of a qualitative study that used in-depth, semi-structured interviews, and the article focuses on the narratives of those that were most pertinent to the themes under discussion. The aim of the study was to bring insight into the particular navigating tools utilised by people living with medically ill-defined conditions in attaining a diagnosis of fibromyalgia in SA (De Vaus, 2001; Weiss, 1995). Ethics clearance was granted by the Ethics Committee of the University of the Witwatersrand. Informed consent was obtained from participants, and pseudonyms were used throughout to maintain their anonymity.

Perspectives from the person at the centre of the processes of diagnosis are vital when investigating illness, especially around conditions that have subjective components of experience. An illness narrative forms a critical part of making sense of and accepting conditions like fibromyalgia (Dennis et al., 2013). As Nettleton et al. (2004: 49) explain,

when a person's account is understood in its socio-biographical context [...] we can begin to gain an insight into the socially embedded, and possibly embodied, nature of people's experiences [... and] the story reveals as much about the culturally available discourses as it does about the minutiae of the teller's life.

Narratives are a necessary and useful means for gaining insight into people's accounts of a complex, often hidden illness experience (Frank, 2010; Keikelame and Swartz, 2013). The narrative approach allows rich, descriptive data to emerge in a unique manner, in that the intersections of smaller, detailed stories reflect on larger, global issues that shape health and illness experiences in systemic ways (Sools, 2013). In drawing out data through this approach, a thematic content analysis was employed to interpret the findings following a framework defined by the central concerns of the study described in this article (Lee and Poole, 2005). Within health research, narrative inquiry has become a salient tool for exploring the accounts of people who experience illness in continuous, chronic forms. Privileging the lived experiences of people whose illnesses have low prestige in medical settings is a growing area of health research (Bleakley, 2005). Crucially, insights into processes, interactions and outcomes that are often hidden from empirical view are offered through this approach.

This study captured both the content of the narratives, as well as how they emerged, and why they were appearing presently (Sools, 2013; Stanley, 2008). For these reasons, narrative inquiry was an appropriate and useful means of uncovering the perspectives of people living with fibromyalgia in SA.

The study did not aim to offer a generalizable account of fibromyalgia. Rather, the purpose was to gain more nuanced understandings of the experience through the narratives of a select group living with the condition in a specific context (Barbour, 2008; Nettleton, 2006). Collecting narrative threads that could connect participants as a community was important. Analysing these experiences in the South African context goes further than many other studies based in this environment. 


\section{Sampling}

In $\mathrm{SA}$, it is likely that only those with access to private health care can see the number and range of specialists needed in pursuing a diagnosis of fibromyalgia (Namane, 2013). The low rate of diagnosis in public health settings possibly means that while people may have fibromyalgia, their illness experience has not yet been defined in terms of the condition. There is a gross maldistribution of health care practitioners and facilities in SA. The majority of specialists operate in the private sector, while the public health system struggles with basic service provision. Therefore, the already arduous process of arriving at the diagnosis of fibromyalgia is exacerbated for those utilising public health care (Mooney and McIntyre, 2008; Namane, 2013) - a situation that explains the social characteristics of the final group of participants in this study. Snowball sampling that was purposive in approach was used to draw participants into the study (Penrod et al., 2003).

Fibromyalgia is poorly understood in SA and is stigmatised as a result. Therefore, seeking participants was a process of connecting the researcher through informal peer networks, and it was important to build trust and rapport with those people who were willing to discuss their experience. The researcher contacted each participant only if they had been diagnosed with fibromyalgia, and had a referral through a peer or acquaintance. Of the 20 people contacted, 15 were ultimately interviewed. A total of 13 of the participants had received a formal diagnosis of fibromyalgia, while 2 had self-diagnosed. The latter were included in the study as their narratives reflected elements of the complex picture that emerged during the course of the research process. The participants were all women aged between 23 and 59 years. All had received their diagnosis in private health care settings. While this implies that fibromyalgia could be seen as a 'diagnosis of the affluent', it is important to note the resources and personal capacity it takes to attain the diagnosis, as discussed earlier (Mclntyre et al., 2003). It is acknowledged that the study sample is not representative of the demographics of SA.

\section{Data collection}

The main body of data was collected using interviews which, according to Barbour (2008), are most suitable for capturing insights into narratives that are detailed and nuanced. Semi-structured interviews were used, and a conversational tone was adopted to foster an environment where the participant's 'small story' could develop as naturally as possible (Sools, 2013).

\section{Data analysis}

Once the interviews had been transcribed, an in-depth thematic analysis was undertaken. The findings that emerged from this process were consistent and rich across the sample, and data saturation was reached when the main themes of the research appeared repeatedly within the interviews. QSR NVivo 10 was used to manage and partially analyse the data along a broad coding frame (Price and Walker, 2014). The analysis is thematically organised to explore the particular issues that emerged across the narratives (Lee and Poole, 2005). The themes that appeared included recognition and legitimacy, credibility, and diagnosis and practitioner encounters. These themes and the findings presented here are grounded in the context of SA, which has shaped the experiences of the participants in allowing the diagnosis to appear, gain traction as an illness experience, and afforded access to treatment and 
further care. The thematic analysis was assistive in linking the small stories of the individual narratives to the big stories of the context, broader debates, and explanations of fibromyalgia experience (Sools, 2013).

\section{Limitations of the study}

While the type of data collected using qualitative methods is rich and descriptive in nature, there is a limitation in the representative capacity of the information. The findings may not be generalizable to the broader population, as is inherently the case in taking a snapshot or particular view of a social phenomenon (Barbour, 2008; Weiss, 1995). The use of individual narratives means that what is discovered in this process might not be able to account for a bigger set of questions related to health and illness experiences (Timmermans, 2013). However, exposing a specific set of stories offers a nuanced insight into the wider processes, actors and institutions that shape health and illness experiences in a specific context (Sools, 2013).

\section{Analysis of findings}

In this section, the findings of the study are discussed within the themes of recognition and legitimacy, credibility, and diagnosis and practitioner encounters. These themes are separated here for clarity, but within the data, elements are interwoven through each anecdote and explanation. Through an integration of literature, theory and data, explanations of patient experiences with fibromyalgia diagnosis in SA is presented.

\section{Recognition and legitimacy}

Werner et al. (2003) usefully describe the notion of a 'recognising attitude', which enables patients and practitioners to frame their experiences and interactions. Many of the symptoms found in chronic pain conditions (particularly the musculoskeletal varieties and fibromyalgia specifically) appear in ordinary existence, though to lesser degrees. This complicates what is seen as legitimate, real and in need of attention. Therefore, the legitimisation of the illness experience requires a recognising attitude from the following actors: the person going through the experience; the family, peers and support network surrounding them; the health care services and providers they can access; and the cultural understandings of pain and exhaustion that circulate in their social environment. An alignment of all these factors precedes an individual seeking a medical explanation for their exceptional and often overwhelming symptoms.

Furthermore, having realised that something is amiss, finding a practitioner that will recognise the symptoms as characteristic of fibromyalgia is not a given. It often requires persistence and insistence on the part of the patient to discover a clinical account of their symptoms (Cunningham and Jillings, 2006). This process is particularly difficult in SA where the number of diagnosed cases and awareness of fibromyalgia is relatively low. Fibromyalgia experience is distinguished by the individual's description of symptoms, and insistence that they are present despite the absence of other biomedical indicators. 
Participants vividly described the character and form of their pain, and how they could distinguish it from discomfort caused by other conditions. $\mathrm{Chloe}^{2}$, a 23-year-old woman who was diagnosed with fibromyalgia in 2007, explained that

There are all sorts of different types of pain; I get all sorts of flavours. A headache is one thing ... but there's nothing to say that's directly linked to fibromyalgia. The most predominant one is just ... it's difficult to explain it. Sometimes it feels like it's my flesh itself ... or my bones are on fire.

Chloe differentiates between pain caused by headaches, and the generalised, indistinct pain she connects to her fibromyalgia. While she struggles to describe it, she notes the multiplicity of the pain she experiences. For her and other participants, the exhaustion too was distinctive in being overwhelming, and sometimes this symptom was more difficult to cope with than the pain. Claire described how

The symptoms really started to become quite difficult ... when I used to go to doctors saying ... because at that point I was still physically very active ... um, so the pain was still quite contained, just headaches, but when I used to go to doctors and say to them ... 'this fatigue is unmanageable ... I can't, I can't do the fatigue'. I think the worst thing that you could do to a doctor is walk into their room and say, 'I'm tired'. [Chuckling].

Here, Claire has spoken about an important aspect of diagnosing fibromyalgia, in that the symptom of exhaustion is ubiquitous across many states of health. For Claire and other participants in this study, telling practitioners that they were 'tired' or fatigued served as the first obstacle in attaining diagnosis, and appeared as a tangible source of derision and delegitimation (May, 2005).

\section{Credibility}

Since fibromyalgia appears alongside and among various conditions, attaining the specific diagnosis is not straightforward, and many participants spoke about their frustration that resulted from unsatisfactory medical consultations. The findings clearly show that diagnosing fibromyalgia presents particular challenges, first in accessing the diagnosis, and then categorising the symptoms under that label. Mendelson's (2009) study on lupus experience showed that the need to seek diagnosis came 'only after the symptoms progressed, were amplified, or repeatedly reoccurred' (p. 398).

Likewise, many of the interviewees had lived with chronic pain and repeating, but intermittent, illness for long periods before being diagnosed with fibromyalgia. Additionally, many of them spoke of the lack of permanency of their symptoms, and the fact that this often caused them to question their diagnosis, seek out new explanations, or move on from fibromyalgia as an illness identity. This could

\footnotetext{
${ }^{2}$ All participant names used in this article are pseudonyms.
} 
be due to the receding severity of fibromyalgia symptoms as they learned to cope with the condition, or because other illnesses had become more overwhelming and pressing.

Frances, a 59-year-old woman, was diagnosed in 1994 while seeking treatment for on-going back problems. At the time, she was told that the practitioners could find nothing else wrong with her. She was then offered antidepressants, implying to her that the problem was psychological in nature. Åsbring and Närvänen (2002) maintain that this is a common result of medical encounters when external, visible signs of illness cannot be found, and the problem is recast as mental illness.

Frances related a later encounter with another health professional who was more helpful in legitimising her experience. She explained

The rheumatologist came along and did a million and one tests and I can remember him walking in and saying 'don't let anyone tell you that it's in your mind', because I had an inflammation level [that] was screamingly high.

Because of the stigma attached to mental illness, there is a well-documented tendency to distance oneself as a patient from a psychological diagnosis, and attempt to constantly reassert the physiological experience and reality of fibromyalgia and associated MUS (Cohen et al., 2011; Lonardi, 2007; Werner and Malterud, 2003). It appears that practitioners are perceived to be dismissive of patients' complaints that are not objectively visible, resulting either from a deliberate shift of responsibility, or from deficient ability (Åsbring and Närvänen, 2002; Mik-Meyer and Obling, 2012; Werner et al., 2004).

Michelle, a 51-year-old woman, explained that she had been diagnosed in 1984 with 'brain attacks', or a severe form of migraines, which were physically disabling for her. Having undergone treatment, she had largely recovered. However, while under the care of a neurologist in 2004, she became convinced that her neurological problems were related to her menstrual cycle, and that the treatment she was receiving was not effective enough. In seeking a clearer answer, she saw an endocrinologist in 2006, who immediately told Michelle that she had fibromyalgia. Her narrative reflects the confusion around the cause of her symptoms, as she could not discern whether it was her neurological condition or her fibromyalgia that created exhaustion for her. The overlapping nature of symptoms, and the conditions that spark them, is a characteristic feature of contested chronic conditions and leads to a 'chaotic' illness experience (Dennis et al., 2013; Meyer, 2006; Nettleton et al., 2004).

In describing her experiences, Michelle also showed a clear sense of wanting more information, both at the point of consulting with the endocrinologist and her general practitioner (GP), as well as the reading she did about fibromyalgia once she had received the diagnosis (van Uden-Kraan et al., 2009). Michelle experienced direct delegitimation of her fibromyalgia diagnosis, as one of her practitioners simply stated that the condition did not exist and it should rather be labelled as depression. This led to Michelle feeling that she, as a fibromyalgia patient, had been discredited along with the label 
(Richardson, 2005). Her ability to call on that diagnosis and the associated positive benefits, such as access to care and treatment, the 'sick role', acceptance and support, were all lost in the face of the disbelief expressed by her practitioner (Aujoulat et al., 2007).

The fact that Michelle's experience could so easily be discredited speaks to the limited currency that fibromyalgia holds in the medical discourse of SA. The lack of convincing elements (like clear biomedical indicators that make the condition objectively visible) leads to reduced credibility (Jutel, 2010). Another contributing element to the insecurity of her diagnosis is that she experiences relative overall wellness, with her 'flare-ups' occurring sporadically and at a much lower level of intensity than she had experienced with her 'brain attacks'. On the spectrum of severity, Michelle's case is mild, in that she has high functionality and has largely adapted her life to accommodate the appearance of symptoms (Audulv et al., 2012). This also adds to her feelings of uncertainty regarding fibromyalgia as being 'real', because her experience is not 'extraordinary' in the context of the illnesses and disabling symptoms she had previously overcome (Richardson, 2005).

\section{Diagnosis and practitioner encounters}

To Frances, fibromyalgia as a diagnosis was

A covering letter, so to speak, for ... chronic pain. But ... and of course [this is complicated by] the fact that there are no diagnostic tests ... $\mathrm{Ja}^{3} \ldots$ it is a difficult thing ... I mean, having been in [a] medical [or] veterinary type [of] environment all my life ... it's really nice to have a blood test that says ... 'this is what it is' ... Vague things don't sit well with one.

Frances had the measurable symptom of inflammation, which let her practitioner anchor her experience in physiological terms, and allowed her to accept her condition more readily. The insistence that she not let her symptoms be reduced to a psychological issue, despite receiving antidepressants as a treatment, illustrated the overall discontinuity caused by attempting to explain fibromyalgia within a purely biomedical framework. This occurs mainly because these conditions are multi-faceted and require holistic approaches (Meyer, 2006).

Frances' case demonstrates the applicability of the label as an encompassing name for a range of symptoms that relate to chronic pain. In using the terminology and framework frequently drawn upon in the literature of fibromyalgia, she acknowledges the utility and frustration contained in the diagnosis (Gardner et al., 2011). Despite recognising the existence of conditions that are not easily categorised, Frances' desire for pinpointed, objective explanations for her illnesses remains (Råheim and Håland, 2006; Richardson et al., 2006).

\footnotetext{
3 'Ja' is Afrikaans for 'yes' and is commonplace in South African speech.
} 
There were two clear routes that the participants followed having received their diagnosis: either they cemented a relationship with their practitioner and continued consultation and help-seeking with them, or they left their doctors' rooms with the label of fibromyalgia and carried on a quest for acceptance, explanation and relief elsewhere. Zainab reflected that

Initially I really ... I thought something ... terrible [was] wrong with me. But you know, when the doctors say, 'no [it's] nothing, it's just pain', this and that ... It took me a long time to realise that there wasn't something seriously wrong with me ... I sort of accepted that maybe this is ... psychological ... I was open to it ... And I decided well, you know, it's up to me; no one else can do anything [for me] but me. And if it's a psychological thing, then it's a matter of me deciding how to ... live with it, or how to manage it.

Inevitably, those who searched further for answers also had greater distrust and difficulty with practitioners than those who found comfort and treatment options that they could adapt to with their health care providers (Gilson, 2003).

Most of the participants had spoken to family and peers, as well as their practitioners about their symptoms, and attempts to make sense of their experiences were explored in these spaces (Cooper and Gilbert, 2016). For many, diagnosis represented a significant turning point in their illness (Frank, 2010). The presence of a 'recognising attitude' among family and friends was a critical resource for them in transforming their symptoms into an illness, and enabling access to diagnosis and treatment (Werner et al., 2003).

In the following narrative, Connie describes the influential role that the 'experts' around her play in suggesting practitioners for her to see, directing her actions and assisting her in taking control of her illness and treatment. In seeking credibility, she embodies the role and behaviours of what Mik-Meyer (2011) refers to as a 'responsible patient':

One day I walked into the [doctors'] rooms, [and] he [the doctor] told me once again 'there's nothing wrong with you', and I told him 'but doctor, this is impossible. I can't sleep, I can't turn, I can't get up from the bed. I have difficulty driving. And you tell me that there's nothing wrong'. He says, 'because there's nothing wrong with you'. I said to him 'fine, then ... I'm going to find [myself] a doctor [who] knows what's wrong with me'. And I managed to find a doctor ... and I put the report [of my medical records] there [on the desk], but I said to the doctor straight away, 'please, I'm going to tell you my problem and then you must tell me, just straight away, can you help me or can you not help me. Are you that doctor to see me?' ... And he looked at me, and he said to me 'you've got what we call fibromyalgia'. I said 'fibro my what?' He says, 'fibromyalgia'. That was the first time I heard fibromyalgia.

Evident in her narrative are the challenges of the condition, in that projecting out a subjective experience was only productive in circumstances where a 'recognising attitude' was present. Having 
encountered contestation and confusion alongside overwhelming symptoms for ten years, Connie was finally offered a name, a label, and an explanation that contextualised her experience in biomedical terms. Obtaining this diagnosis was intrinsically linked to her access to care through private medical insurance, which afforded her multiple visits to a range of practitioners while seeking a satisfactory explanation for her symptoms (Namane, 2013). The diagnosis made her experience acceptable and recognised as a condition, and allowed her to embody the 'sick role' of a fibromyalgia patient (van Hal et al., 2013).

Claire's narrative highlights the role of peer group support and self-diagnosis in coming to the label of fibromyalgia as the explanatory mechanism for her symptoms (Gage, 2013). Having experienced disconfirmation and scepticism from many people in her life, particularly her family and her practitioners, she was cautious about discussing her perspectives of her symptoms and illness. A chance encounter with a peer led to her discovering the practitioner who eventually officially diagnosed her with fibromyalgia and who offered a tailored treatment regimen that was designed specifically for the condition. Claire discovered the same turning point in her fibromyalgia illness career that other participants described, despite having initially self-diagnosed. She expressed that finding a GP who accepted her condition proved to be a crucial element in shaping her illness experience and outcomes positively

I think what made it safe for me to take the diagnosis to the doctor was the fact that I'd built up quite a solid relationship with him ... And I just felt that he was very engaging and it felt ... [as if] he took me seriously, [and he] regarded me as a person capable of making my own thoughts and reaching my own conclusions, and I think that's what made it safe for me to take the diagnosis to him. I don't think I would have done that with a lot of other doctors.

Like Claire, Connie also received a clear explanation of the label of fibromyalgia when she was diagnosed, though a treatment route could not be dispensed by Connie's practitioner (Rosenzweig and Thomas, 2009). What Connie's doctor could do was to locate her current illness in the context of her life and medical history, and identify the interplay between her actions and symptom onset. He was also able to explain that particular activities would exacerbate her condition, and how she could avoid them. Her doctor described her pain in terms of muscles and the strain they felt. She relayed that

[My doctor] says, 'what this muscle is saying to you is, 'ja right, you think you're going to pull me while I'm already like this, I'm going to show you and I will make you pay for the stretch that you've just done here". And [he explained that] then ten minutes later when it becomes cold, that's when the inflammation is there [in that muscle].

The narrative shows the complexity of a condition like fibromyalgia, in that it is so intricately tied to everyday living, and a bad movement or muscle pull appears unpredictably, making it difficult to avoid the action (May, 2005; Morris et al., 2012). As Chloe plainly stated, a flare-up can occur at any time, as 'there is no fixed trigger. Whether you do something right or wrong, it can happen'. 
As discussed, fibromyalgia requires holistic and flexible approaches that respond to the condition as a complex entity, where the offer of effective treatment supersedes the need to account for the causes and manifestations in a rigid set of narrow categories (Eriksson, 2015). The biomedical establishment is a powerful bureaucratic institution in many societies, and SA is no exception. As the official source of health care and knowledge, it maintains its prominent position through its effectiveness in dealing with matters of health and illness. There are also disparities within the structure that produce differential outcomes in the experience of interacting with the institution, its facilities, practitioners, and support structures, such as medical aid schemes (Potter and McKinlay, 2005).

The dissemination of knowledge and practice standards within the institution of biomedicine is also uneven and the consequence of this process is that approaches, information and treatments are applied in a scattered manner that often do not support the patient (Mik-Meyer and Obling, 2012; Raff et al., 2014). The patient increasingly becomes the 'expert' on their health and their condition (Madden and Sim, 2016). While biomedicine and its practitioners continue to play a supportive role in the process, much of the information, care and treatment for the patient is located outside of the institution (Wolfe et al., 2011).

Some participants experienced rejection, or felt the diagnosis offered was not accurate, and in turn they distanced themselves from biomedicine as the primary source of knowledge and care for their condition. Helena commented that

The pain was extremely debilitating. It was often intolerable. You start the cycle of painkillers and non-inflammatory [medications] and all those sorts of things. Nobody could help me. They then started to send me to the realms of the specialists. Incredibly expensive on every level. Physically expensive, emotionally expensive, psychologically [expensive]. You take a battering, because everywhere you turn, nobody finds anything, and yet you know that you're experiencing this. And sadly they don't ... the medical profession is not a particularly empathetic profession. You find exceptions, and I had the opportunity to work with some very caring physicians, but they were still unable to give me answers, and [through a] process of elimination over three or four years, I eventually got to a rheumatologist at the Sandton Clinic who diagnosed me ... [he] was particularly unhelpful and simply told me I should take an antidepressant because I was depressed.

While the experience of pain, and associated medical conditions, are often poorly understood, there is partial acceptance and support offered within biomedical practice (Råheim and Håland, 2006). The difficulty becomes impactful in instances of illness where the person and their conditions are rejected in some aspect of their care and treatment, despite receiving initial accommodation (Madden and Sim, 2016). This emerged in the narratives collected through this research process, as people with fibromyalgia encountered legitimacy when they were offered a diagnosis. However, the participants subsequently felt that their experience was allocated diminished credibility when their practitioners, and the biomedical knowledge and practice drawn upon in their interaction, did not result in curative 
treatment, or even reduced symptom severity, or when they were offered psychological diagnosis and treatments (Kirmayer et al., 2004).

This is further exacerbated when the patient re-enters society after these interactions and finds that they are unable to draw on care and support from other institutions (Ell, 1996; Eriksson, 2015). These include workplaces, family and peers, and the medical aids that play a critical role in accessing and financially supplementing consultation and treatment in SA (Cooper and Gilbert, 2016). Fibromyalgia requires belief, which is effected through a recognising practitioner and an articulate patient. The interaction has to take place in an environment that accepts the diagnosis for its nuance, complexity and multiplicity if it is to be productive (Campbell et al., 2011; Ong et al., 1995; Raff et al., 2014).

\section{Discussion and conclusion}

This study explored the complexity of attaining a diagnosis of fibromyalgia in SA through the narratives of people living with the condition. Indeed, for the people in this study, the additional complication of variable access to health care shaped the ability to pursue diagnosis and continue treatment. By focusing on the participants' individual experiences of the disease trajectory, this study offers a comprehensive and nuanced understanding of this taxing process in an unaccommodating environment. The findings illuminate the multi-layered contestations experienced by those living with fibromyalgia.

It becomes immensely difficult for the patient to articulate and separate what is usually a multitude of symptoms into different experiences and conditions, each of which come with their own names, expectations, outcomes and treatments (Madden and Sim, 2016). As Cunningham and Jillings (2006) note in their study of fibromyalgia experience, there are many complications that result from a 'constellation of interacting factors ... [and their participants] continued to encounter scepticism and lack of support from friends, colleagues, and health professionals, due to the invisibility of FM and its questionable legitimacy in the minds of some health care providers' (pp. 267-268). The findings of this study confirm Cunningham and Jillings' (2006) assessment of fibromyalgia as a challenging diagnosis and illness experience. The fact that it is only available to people who have access to private resources beyond the public health system confounds the process and adds a level of complexity related to diagnosis and treatment in the South African context that calls for further research.

\section{Acknowledgements}

The authors acknowledge the invaluable contribution of the participants of this study, and thank them for their generosity, perspectives and insight. This article is based on research conducted by Silvie Cooper as part of her PhD in Health Sociology and was supervised by Leah Gilbert.

\section{Declaration of Conflicting Interests}

The author(s) declared no potential conflicts of interest with respect to the research, authorship, and/or publication of this article. 


\section{Funding}

The author(s) disclosed receipt of the following financial support for the research, authorship, and/or publication of this article: This work was supported by the University of the Witwatersrand, the National Research Foundation and the Andrew W. Mellon Foundation.

\section{References}

Ablin, JN, Buskila, D, Van Houdenhove, B. (2012) Is fibromyalgia a discrete entity? Autoimmunity Reviews 11(8): 585-588.

Åsbring, P, Närvänen, A-L (2002) Women's experiences of stigma in relation to chronic fatigue syndrome and fibromyalgia. Qualitative Health Research 12(2): 148-160.

Åsbring, P, Närvänen, A-L (2004) Patient power and control: A study of women with uncertain illness trajectories. Qualitative Health Research 14(2): 226-240.

Audulv Å, Asplund, K, Norbergh, K-G (2012) The integration of chronic illness self-management. Qualitative Health Research 22(3): 332-345.

Aujoulat, I, Luminet, O, Deccache, A (2007) The perspective of patients on their experience of powerlessness. Qualitative Health Research 17(6): 772-785.

Barbour, R (2008) Introducing Qualitative Research: A Student's Guide to the Craft of Doing Qualitative Research. London: SAGE.

Barker, KK (2011) Listening to Lyrica: Contested illnesses and pharmaceutical determinism. Social Science \& Medicine 73(6): 833-842.

Berger, A, Dukes, E, Martin, S. (2007) Characteristics and healthcare costs of patients with fibromyalgia syndrome. International Journal of Clinical Practice 61(9): 1498-1508.

Bleakley, A (2005) Stories as data, data as stories: Making sense of narrative inquiry in clinical education. Medical Education 39(5): 534-540.

Campbell, P, Wynne-Jones, G, Dunn, KM (2011) The influence of informal social support on risk and prognosis in spinal pain: A systematic review. European Journal of Pain 15(5): e1-e14.

Chetty, S, Baalbergen, E, Bhigjee, Al. (2012) Clinical practice guidelines for management of neuropathic pain: Expert panel recommendations for South Africa. SAMJ: South African Medical Journal 102(5): 312-325.

Cohen, M, Quintner, J, Buchanan, D. (2011) Stigmatization of patients with chronic pain: The extinction of empathy. Pain Medicine 12(11): 1637-1643.

Cooper, S, Gilbert, L (2016) The role of 'social support' in the experience of fibromyalgia - narratives from South Africa. Health and Social Care in the Community. DOI: 10.1111/hsc.12403.

Coovadia, H, Jewkes, R, Barron, P. (2009) The health and health system of South Africa: Historical roots of current public health challenges. The Lancet 374(9692): 817-834. 
Cunningham, MM, Jillings, C (2006) Individuals' descriptions of living with fibromyalgia. Clinical Nursing Research 15(4): 258-273.

De Vaus, D (2001) Research Design in Social Research. Thousand Oaks, CA: SAGE, pp. 1-52.

Dennis, NL, Larkin, M, Derbyshire, SWG (2013) "A giant mess" - making sense of complexity in the accounts of people with fibromyalgia. British Journal of Health Psychology 18(4): 763-781.

Dommerholt, J, Issa, TS (2010) Differential diagnosis of fibromyalgia (chapter 8). In: Chaitow, L, Baldry, P, Blake, E. (eds) Fibromyalgia Syndrome. 3rd ed. Edinburgh: Churchill Livingstone, pp. 179-213.

Dumit, J (2006) Illnesses you have to fight to get: Facts as forces in uncertain, emergent illnesses. Social Science \& Medicine 62(3): 577-590.

Ell, K (1996) Social networks, social support and coping with serious illness: The family connection. Social Science \& Medicine 42(2): 173-183.

Eriksson, L (2015) Diagnosis at work: On sick leave in Sweden. Social Theory \& Health 13: 162-179.

Eyles, J, Harris, B, Fried, J. (2015) Endurance, resistance and resilience in the South African health care system: Case studies to demonstrate mechanisms of coping within a constrained system. BMC Health Services Research 15, 432.

Frank, AW (2010) Letting Stories Breathe: A Socio-Narratology. Chicago, IL: University of Chicago Press.

Gage, EA (2013) Social networks of experientially similar others: Formation, activation, and consequences of network ties on the health care experience. Social Science \& Medicine 95: 43-51. Gardner, J, Dew, K, Stubbe, M. (2011) Patchwork diagnoses: The production of coherence, uncertainty, and manageable bodies. Social Science \& Medicine 73(6): 843-850.

Gilson, L (2003) Trust and the development of health care as a social institution. Social Science \& Medicine 56(7): 1453-1468.

Govender, CO (2004) The psychological profiles of Fibromyalgia patients: Towards a model of taxonomy and maintenance of the illness. MA Thesis, University of Pretoria, Pretoria, South Africa. Available at: http://upetd.up.ac.za/thesis/available/etd-03062006-095005/ (accessed 21 April 2012).

Govender, RC, Oosthuizen, P, Cloete, KJ (2011) Diagnostic outcome of patients referred to psychiatry with medically unexplained symptoms: A retrospective study. African Journal of Psychiatry 14(1): 4549.

Greco, M (2012) The classification and nomenclature of 'medically unexplained symptoms': Conflict, performativity and critique. Social Science \& Medicine 75(12): 2362-2369.

Jutel, A (2010) Medically unexplained symptoms and the disease label. Social Theory \& Health 8(3): 229-245.

Jutel, A, Nettleton, S (2011) Towards a sociology of diagnosis: Reflections and opportunities. Social Science \& Medicine 73(6): 793-800.

Keikelame, MJ, Swartz, L (2013) A lay carer's story about epilepsy in an urban South African context: They call it an illness of falling or an illness of fitting because a person shakes and eventually falls. Epilepsy \& Behavior 28(3): 512-518. 
Kirmayer, L, Groleau, D, Looper, K. (2004) Explaining medically unexplained Symptoms. Canadian Journal of Psychiatry 49: 663-671.

Lee, AM, Poole, G (2005) An application of the transactional model to the analysis of chronic illness narratives. Qualitative Health Research 15(3): 346-364.

Lonardi, C (2007) The passing dilemma in socially invisible diseases: Narratives on chronic headache. Social Science \& Medicine 65(8): 1619-1629.

Lupton, D (2003) Medicine as Culture. London: SAGE.

Mclntyre, D, Doherty, J, Gilson, L (2003) A tale of two visions: The changing fortunes of social health insurance in South Africa. Health Policy and Planning 18(1): 47-58.

Mclntyre, D, Thiede, M, Nkosi, M. (2007) SHIELD work package 1 report: A critical analysis of the current South African health system. Report, University of Cape Town and University of the Witwatersrand, South Africa, April.

Madden, S, Sim, J (2016) Acquiring a diagnosis of fibromyalgia. Social Theory \& Health 14(1): 88-108.

May, C (2005) Chronic illness and intractability: Professional-patient interactions in primary care. Chronic Illness 1(1): 15-20.

Mendelson, C (2009) Diagnosis: A liminal state for women living with lupus. Health Care for Women International 30(5): 390-407.

Meyer, HP (2006) Fibromyalgia syndrome: Current concepts. South African Family Practice 48(3): 2028.

Mik-Meyer, N (2011) On being credibly ill: Class and gender in illness stories among welfare officers and clients with medically unexplained symptoms. Health Sociology Review 20(1): 28-40.

Mik-Meyer, N, Obling, AR (2012) The negotiation of the sick role: General practitioners' classification of patients with medically unexplained symptoms. Sociology of Health \& Illness 34(7): 1025-1038.

Mooney, GH, Mclntyre, DE (2008) South Africa: A 21st century apartheid in health and health care? Medical Journal of Australia 189(11): 637-640.

Morris, L, Grimmer-Somers, KA, Louw, QA. (2012) Cross-cultural adaptation and validation of the South African Pain Catastrophizing Scale (SA-PCS) among patients with fibromyalgia.

Namane, MK (2013) Consultation outcomes for musculoskeletal conditions at two community health centres in Cape Town. South African Family Practice 55(4): 380-384.

Nettleton, S (2006) The Sociology of Health and Illness. Cambridge: Polity Press.

Nettleton, S, O'Malley, L, Watt, I. (2004) Enigmatic illness: Narratives of patients who live with medically unexplained symptoms. Social Theory \& Health 2(1): 47-66.

Ong, LML, de Haes, JCJM, Hoos, AM. (1995) Doctor-patient communication: A review of the literature. Social Science \& Medicine 40(7): 903-918.

Padarath, A, Chamberlain, C, McCoy, D. (2003) Health Personnel in Southern Africa: Confronting Maldistribution and Brain Drain. Durban, South Africa: Health Systems Trust. 
Penrod, J, Bray Preston, D, Cain, RE. (2003) A discussion of chain referral as a method of sampling hard-to-reach populations. Journal of Transcultural Nursing 14(2): 100-107.

Potter, SJ, McKinlay, JB (2005) From a relationship to encounter: An examination of longitudinal and lateral dimensions in the doctor-patient relationship. Social Science \& Medicine 61(2): 465-479.

Price, E, Walker, E (2014) Diagnostic vertigo: The journey to diagnosis in systemic lupus erythematosus. Health 18(3): 223-239. Google Scholar, SAGE Journals

Råheim, M, Håland, W (2006) Lived experience of chronic pain and fibromyalgia: Women's stories from daily life. Qualitative Health Research 16(6): 741-761.

Raff, M, Crosier, J, Eppel, S. (2014) South African guideline for the use of chronic opioid therapy for chronic non-cancer pain. South African Medical Journal 104(1): 79-89.

Richardson, JC (2005) Establishing the (extra) ordinary in chronic widespread pain. Health 9(1): 31-48.

Richardson, JC, Ong, BN, Sim, J (2006) Remaking the future: Contemplating a life with chronic widespread pain. Chronic Illness 2(3): 209-218.

Rosenzweig, TM, Thomas, TM (2009) An update on fibromyalgia syndrome: The multimodal therapeutic approach. American Journal of Lifestyle Medicine 3(3): 226-237.

Sim, J, Madden, S (2008) Illness experience in fibromyalgia syndrome: A metasynthesis of qualitative studies. Social Science \& Medicine 67(1): 57-67.

Skuladottir, H, Halldorsdottir, S (2011) The quest for well-being: Self-identified needs of women in chronic pain. Scandinavian Journal of Caring Sciences 25(1): 81-91.

Sools, A (2013) Narrative health research: Exploring big and small stories as analytical tools. Health 17(1): 93-110.

Stanley, L (2008) Madness to the method? Using a narrative methodology to analyse large-scale complex social phenomena. Qualitative Research 8: 435-447.

Stuckler, D, Basu, S, McKee, M (2011) Health care capacity and allocations among South Africa's provinces: Infrastructure-inequality traps after the end of Apartheid. American Journal of Public Health 101(1): 165-172.

Timmermans, S (2013) Seven warrants for qualitative health sociology. Social Science \& Medicine 77: $1-8$.

Van Hal, L, Meershoek, A, Nijhuis, F. (2013) Disembodied abilities: Sick role and participation in 'activating' return-to-work practices. Social Science \& Medicine 96: 9-16.

Van Uden-Kraan, CF, Drossaert, CHC, Taal, E. (2009) Participation in online patient support groups endorses patients' empowerment. Patient Education and Counseling 74(1): 61-69.

Weiss, R (1995) Learning from Strangers: The Art and Method of Qualitative Interview Studies. New York: Free Press.

Werner, A, Malterud, $\mathrm{K}$ (2003) It is hard work behaving as a credible patient: Encounters between women with chronic pain and their doctors. Social Science \& Medicine 57(8): 1409-1419. 
Werner, A, Isaksen, LW, Malterud, K (2004) 'I am not the kind of woman who complains of everything': Illness stories on self and shame in women with chronic pain. Social Science \& Medicine 59(5): 10351045.

Werner, A, Steihaug, S, Malterud, K (2003) Encountering the continuing challenges for women with chronic pain: Recovery through recognition. Qualitative Health Research 13(4): 491-509.

Wolfe, F (2010) New American College of Rheumatology criteria for Fibromyalgia: A twenty-year journey. Arthritic Care \& Research 62(5): 583-584.

Wolfe, F, Häuser, W, Hassett, AL. (2011) The development of fibromyalgia - I: Examination of rates and predictors in patients with rheumatoid arthritis (RA). PAIN 152: 291-299.

\section{Author biographies}

Silvie Cooper, PhD, is a research associate at the University of the Witwatersrand, Johannesburg. Her research and publications are primarily focused on fibromyalgia and other chronic illnesses, narrative methodology, peer education and sexuality, and digital health. She is currently working on an effectiveness study of an online self-management intervention for patient education.

Leah Gilbert is emeritus professor of Health Sociology at the University of the Witwatersrand. Her research interests encompass the links between society, health, disease and the health professions and she has published widely on social aspects of dentistry, the role of pharmacy in primary health care, medical and health care pluralism, the role of health professionals in the response to HIV/AIDS and the associated social complexity of HIV/AIDS with the focus on gender, age and stigma. Her current research explores the nature of retirement in academia as well as grandparenthood in an era of digital technology. 